\title{
Introduction and Maintaining Public Relations of SMALL ENTERPRISES IN VIRTUAL ENVIRONMENT
}

\author{
Berislav Andrlic, Kresimir Lackovic \& Martin Stimac
}
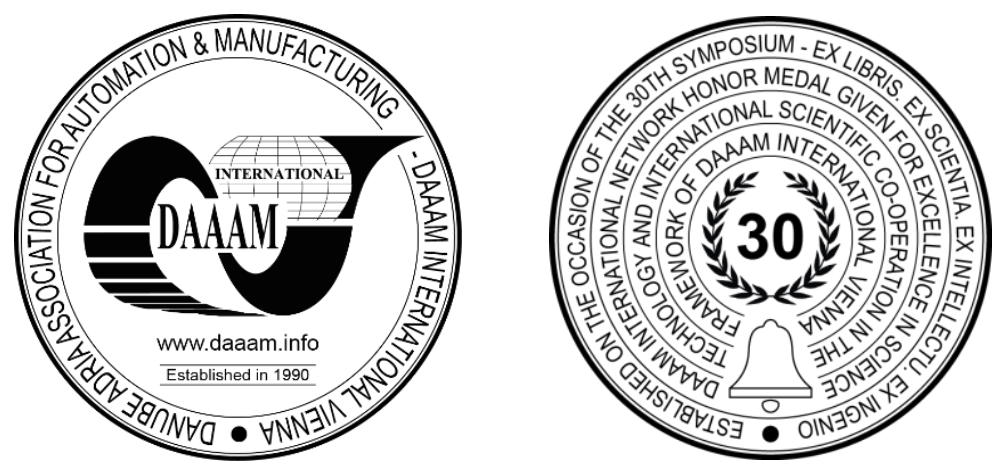

This Publication has to be referred as: Andrlic, B[erislav]; Lackovic, K[resimir] \& Stimac, M[artin] (2021). Introduction and Maintaining Public Relations of Small Enterprises in Virtual Environment, Proceedings of the 32nd DAAAM International Symposium, pp.0009-0015, B. Katalinic (Ed.), Published by DAAAM International, ISBN 9783-902734-33-4, ISSN 1726-9679, Vienna, Austria DOI: $10.2507 / 32$ nd.daaam.proceedings.002

\begin{abstract}
In this paper, the object of consideration is a small company and as a subject and goal is to explore an effective model of introducing and maintaining public relations. In this sense, the methods of analysis and synthesis, ie induction and deduction, as well as abstraction and modeling, have been applied. The researched data indicate a large participation of small enterprises in terms of employment and social product creation, but also their participation in the dynamization of the national economy. Special attention is paid to public relations and it starts from the scientific assumption that in small companies it is not only a marketing but also a managerial activity. In addition, the goal is to research the model of introducing and maintaining public relations and defining the process of activities at the lowest possible cost. Therefore, the second hypothesis implies that the development of information technologies enables the setting up of a public relations process via the Internet with the aim of cost and time efficiency. From this approach, a model is proposed as the final solution for the effective introduction and maintenance of public relations in small businesses.
\end{abstract}

Keywords: Public Relations; Small Business; Internet; Information Technology

\section{Introduction}

Every company is part of the wider community, so in addition to the market, it must respect and maintain exemplary and mutually beneficial relations with the rest of the public. According to the already established definitions, public relations or English Public Relations (hereinafter also PR) are part of the promotion tool as an element of the marketing mix. The object of consideration are small enterprises, which play a major role, especially in developed economies. For example, in the U.S. economy, there are more than 27 million small businesses that generate about $50 \%$ of U.S. domestic product [4].

In modern conditions, and especially in small companies, PR is becoming an increasingly important managerial activity because all managerial and creative work in most cases is performed by one person or owner-manager. [2] Therefore, in the mutual interest, it should maintain appropriate relations with the relevant public, such as: customers and suppliers, local self-government and financial institutions, the media, and existing databases and centers of excellence. 
This is extremely important because the company is an integral part of the social and economic being of the community, whether local or national, so it is obliged to conduct its business in a way that improves the social and economic progress of the community, and not to hinder. [5]. In addition, the PR of every small business must deal with the overall image and reputation of the company as an entity in its environment. [6].

Given the limited costs, but also time, a small entrepreneur does not have great opportunities to establish and maintain relationships with the relevant public. Information technology can help him here, especially the recently ubiquitous social networks. [1] The development of information technologies provides the entrepreneur with the opportunity to achieve all PR goals with a minimum of time and costs. In this sense, the hypothesis is set that by systematic introduction in stages with the aim of establishing and maintaining PR, all business and especially marketing goals can be achieved. Given that the object of this paper is a small company and as a subject and goal to research an effective model of introducing and maintaining public relations, appropriate scientific research methods have been applied. In order to determine the basic characteristics and role of small enterprises in national economies, but also the function of managers, methods of analysis and synthesis, ie induction and deduction, were applied. These methods have also been used in researching and identifying opportunities offered by Internet technologies as a public relations support. By applying the methods of abstraction and modeling, a phased approach to the introduction and maintenance of public relations in small enterprises is defined.

As part of the consideration and research in the text, attention is paid to the special features of a small business as an object of research. The research related to the development of public relations has covered a part of historical development. From a corporate perspective, the first PR department was established in 1889 at Westinghouse for the purpose of promoting a revolutionary AC system. In addition, at Jale University in 1899, the secretary's office was successfully converted into an office for former student and public relations officials. [7].

With the development of information technology, public relations activities have increasingly taken place on the Internet to communicate with potential and current customers in order to provide desirable information about the company, which greatly reduces unwanted comments. Public relations can accelerate and expand the distribution of press releases especially in today's global and highly dynamic market. In addition, interactive two-way and multi-way communication as well as communication mediation can be realized via the Internet. In most cases, Internet PR aimed to influence the external image of a company or brand with the following tasks: [8].

- Acquisition and retention of new customers

- Communication and information

- Increasing public attention

- Creating a high cost-benefit ratio

- Improving reputation

- Measuring and managing success

- Achieving a high degree of topicality

The main feature of these beginnings of the Internet approach to PR is the asynchronous flow of communications because communication did not take place in real time. Teaching development went in the direction of modeling with the aim of increasing mutual synergy between companies and the public. The analysis of the development of possibilities of information technologies shows that different approaches are possible, and on this occasion the systematic introduction of PR by phases was chosen. Such an approach ensures the gradual introduction of the public relations function on the one hand and the education of entrepreneurs on the other. The discussion with concluding remarks has the purpose of explaining the research and warning about the proposed possibilities arising from the proposed PR model and introduction by stages. From the above considerations, it is clear that PR is a strong managerial activity in a small business that can be performed in an online environment with minimal loss of time and negligible costs. The continuation of this research is aimed at monitoring the development of public relations and especially information technologies and continuous education with the aim of effective application.

\section{Elementary characteristics of small business}

In modern conditions, most, especially developed economic systems, are made up of a large number of small enterprises, but most employees are also in small and medium enterprises. It has long been known that data on small business appeared 4,000 years ago. According to data on the U.S. economy from 30 years ago, $88.9 \%$ of employees worked in companies with up to 10 employees and $91.3 \%$ in companies with up to 20 employees. To this can be added the indicative data that $99.1 \%$ of employees worked in companies that had less than 100 employees. Of course, not all companies are successful because there is data that in the US out of 600,000 new companies established annually, only half will live 18 months, and only a fifth ten years, but a similar number of new small businesses will be reactivated next year. From the previous data, it can be concluded how dynamic such an economy is. Therefore, the success of any economic system is based on the performance and volume of small businesses.

In modern conditions in the Republic of Croatia, according to the Act on the Promotion of Small and Medium-Sized Entrepreneurship, the sphere of small business has been formed, which consists of micro, small and medium-sized enterprises. They vary in size based on the following characteristics:[8]: 


\section{Micro small business entities (natural and legal persons)}

- employ less than 10 workers (annual average).

- generate annual operating income in the amount of the equivalent of up to EUR 2,000,000.00, or have total assets if they are taxpayers of profit tax, or have fixed assets if they are taxpayers of income tax, in the amount of the equivalent of up to EUR 2,000,000.00.

\section{Small business entities (natural and legal persons)}

- have less than 50 employees (annual average)

- earn annual operating income in the amount of the equivalent of up to EUR 10,000,000.00, or have total assets if they are taxpayers of profit tax, or have fixed assets if they are taxpayers of income tax, in the amount of the equivalent of up to EUR 10,000,000.00

\section{Medium-sized small businesses (individuals and legal entities)}

- have less than 250 employees (annual average)

- generate annual operating income in the amount of the equivalent of up to EUR 50,000,000.00, or have total assets if they are taxpayers of profit tax, or have fixed assets if they are taxpayers of income tax, in the amount of the equivalent of up to EUR 43,000,000.00.

According to the Report on Small and Medium-Sized Enterprises in Croatia for 2018, the importance of small and medium-sized enterprises is visible. Namely, in the period from 2013 to 2017, the numerical department of micro and small enterprises in the total number of economic entities in their years was $98 \%$. If small and micro enterprises are added to medium, then their percentage is $99.7 \%$. This means that special attention should be paid in the research of smaller economic entities in order to find various innovations whose application can enable the stability of these entities. [3] This is especially important due to the fact that even in developed economies, many small start-ups do not last. In addition to this information, the fact that small businesses have advantages and certain disadvantages should be taken into account. [9]. Small businesses have the following advantages:

- In a small business, each employee feels part of a shared process.

- There is a greater opportunity to highlight personal particularly professional ambitions.

- Every employee feels an appropriate share of responsibility.

- A small business will be more productive and with a greater degree of discipline.

- Almost all interested employees can be involved in development programs.

In addition to the obvious advantages, the following disadvantages should be borne in mind:

- Insufficient knowledge, especially in the field of finance and informatics-

- Patriarchal leadership.

- Insufficient level of group decision making.

- Great reliance on improvisation and intuition.

- Overloaded with a large number of functions.

- Insufficient use of the achievements of the development of technique and technology.

These advantages, and especially the disadvantages of small businesses, suggest that there is considerable scope for researching the way businesses do business and imposing proposals to increase the efficiency of small businesses. As already mentioned in small businesses, the owner is in most cases a manager, so he is responsible for almost all creative and management functions and thus marketing. [4] As part of the marketing mix or promotion as part of sales promotion are public relations. Further research shows that especially in small businesses, public relations is becoming an increasingly important managerial activity. Therefore, in modern online conditions, in order to reduce costs, public relations should be performed with the help of Internet technologies.

\section{Public relations in modern conditions- virtual environment}

Since all marketing activities are usually performed by one person or owner-manager in a small business, this must be supported by information technology. [5] Namely, in a large number of cases, all production and marketing activities are contained in one person or manager who is also the owner of a small business. In this sense, it is necessary to research the market, which means to find a group of consumers who will be similar in their reactions to the products offered and to identify a group that will behave similarly in buying and consuming, which means to determine the market segment. Similar procedures are carried out in the procurement as well as in the sales market. After determining the market segment of purchasing and sales, one constant marketing activity or promotion is needed. Promotional activities can be done in different ways, in the form of advertising, personal sales and sales promotion. Special attention should be paid to public relations activity. There are several definitions of this activity and in this case we have the following: "Public relations is a decision-making practice that has the task of building relationships and interests between organizations and their publics by providing information using communication methods that are ethical and trustworthy." 
In terms of publicity in the company's environment are: the media, customers and suppliers, financial institutions, local government and databases. In a situation where usually one person needs to perform all management and creative activities, an extremely important factor is cost and time. In addition to limiting costs, there are research results where $60 \%$ of respondents-entrepreneurs believe that PR, along with operations, is an important managerial strategic activity. [10]. Therefore, it is proposed in the organizational structure of a small business that PR be, in addition to tools to improve sales, one of the important activities of managers or owners of small businesses.

\section{Introducing and maintaining public relations in an online environment}

After the necessary IT education, a small entrepreneur can gradually approach the introduction of PR, and the Internet is becoming an increasingly important tool. According to Figure 1, it is recommended that this be done in stages, because in this way the process of PR development and IT education of entrepreneurs will take place in parallel, ie how to use new information technologies and different information platforms for their own public relations.

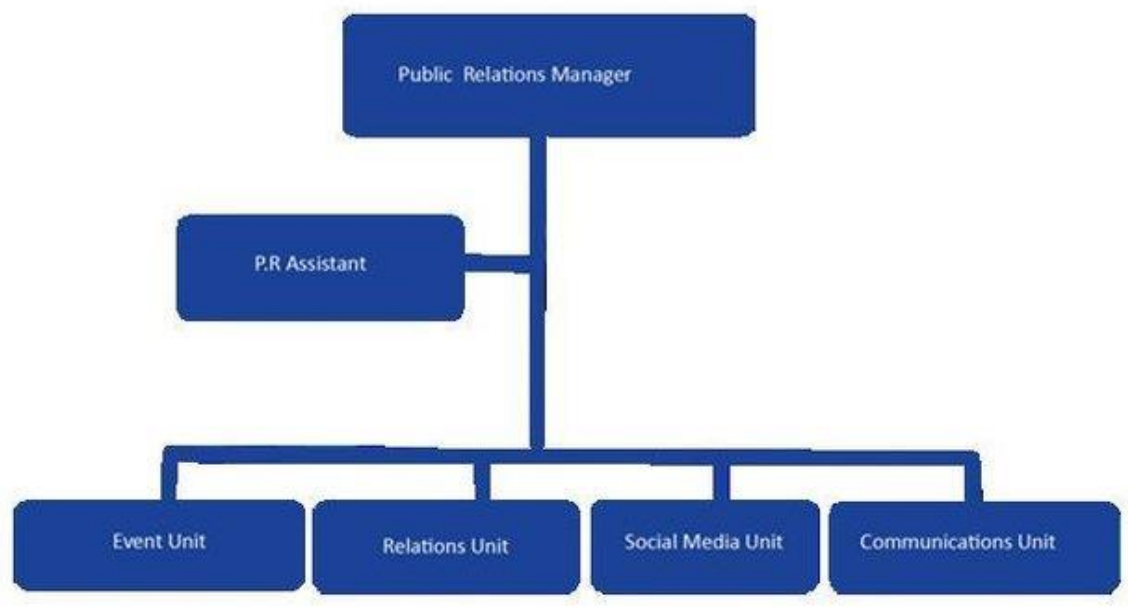

Fig. 1. Proposal of PR organizational structure of a small business

The above process in Figure 1 should be correlated with the development of information hardware and software. It all started when a networked hypertext system was developed for CERN called the World Wild Web (www for short) that included HTML language and HTTP protocol, so after installing it on a computer, the first web server was created. After that, the possibility of connecting the www network with other computers was developed and Web 1.0 was developed, as well as connecting commercial and non-commercial networks, which became cheaper. [6]

Opening a web portal or profile on the most famous social networks is the minimum that every new entrepreneur should do. With the help of this, in a short time it will determine the possible boundaries of the market segment and even the group of the most important customers and suppliers. After determining the market segment and the grouping of the most important customers and suppliers, the entrepreneur can move on to the next phase, which is a personalized web portal. The main goal of personalization is to deliver information that is important to an individual or group of individuals among customers and suppliers in a specific form, schedule and time intervals. [11].

At this stage of development, the PR entrepreneur already addresses his public directly, which means that he communicates asynchronously because he can get answers and comments after his information. In this way, conditions were created for other sections of the public to be involved in order to participate in the discussion. This type of discussion is known as a forum which is actually the technological evolution of bulletin boards. From a technological point of view, forums or web boards are applications that manage user-generated content. Early online forums could be described as a web version of an electronic list or newsgroup; allowing people to post messages and comment on other messages. Subsequent developments have mimicked different newsgroups or individual lists, providing more than one forum, dedicated to a particular topic. The team has the opportunity to provide additional information about their own products and services and to reconcile common interests. [7]

The development of information technologies on the one hand and the entrepreneur's education in the next phase enables synchronous communication through video conferencing, which is organized by agreement from time to time with all interested sections of the public. Videoconferencing is the connection of individuals and groups through telecommunications networks and video technology so that participants have the impression of simultaneously attending meetings in the form of a live video link on a computer screen. This type of synchronous discussion provides an opportunity for all participants to inform each other, but also to draw conclusions of mutual interest. After the establishment of PR with all participants in the previous stages in the coming period should ensure the sustainability and effectiveness of established relationships. 
Additional features that maintain and refresh PR can be social networks, which in principle can be defined as a webbased service that allows an individual to create a (semi) public profile and within a limited system, articulates a list of other users with whom he shares connections and sees and compares his list. contacts with those made by other users within the system. [12].

There are many ways in which a social network can be used, such as: creating your own profile, areas of interest and preferences, searching for and finding old or making new friends, exchanging pictures and videos, but you can become a member of certain interest groups. There are several types of social networks, and on this occasion, Facebook, Instagram and Linkedin will be especially highlighted. The concept of Facebook was designed to connect people who already know each other in real life via the Internet. The main feature of Facebook are numerous applications because, for example, it is possible to have virtual pets, receive virtual gifts and greeting cards, solve quizzes and play video games. Facebook offers the possibility of privacy control, so the user can hide their profile and photos and protect themselves from unknown visitors. Instagram is a popular free app for processing and sharing photos via mobile phones on social networks. Linkedin is a business-oriented social networking service and is mainly used for professional networking especially in recruitment and sales. All these social networks provide the opportunity to personalize each other's information after synchronous discussions. This means that the entrepreneur creates even closer relationships with customers and suppliers, but also with the rest of the public. In that way, a long-term connection is realized with minimal costs and loss of time.

In order to successfully apply the proposed phased approach, positive attitudes and suggestions were made to pay special attention to the following: [12].

- Providing information on the website on aspects such as investor relations, organizational programs and policies, community involvement and employee relations. This could open the door for public participation and debate.

- Creating a forum for comments and suggestions. This forum could function as a chat room where a visitor can enter a message and receive an immediate response from a company representative or another visitor. Such a forum could function like a 24-hour, 7-day focus group. [8]

- Intuitiveness and ease of display is required along with a hierarchical relationship between graphics and text in order to promote efficiency and download speed, as too many graphics can bother users who are short of time. Websites should not be designed to be accessible only to users who have the latest hardware or software but should be interesting, informative and contain valuable information to all visitors. Graphics and sounds must be useful tools, but content should take precedence over aesthetic considerations. Dialogic public relations must create lasting and valuable relationships with your public and therefore the website must not be used just as propaganda, marketing or an advertising tool.

- In order to obtain a return of visits, the first important element is the need for useful and timely information for various publics.

- Websites that provide limited or immutable information will not generate repeat visits because after one visit they are no longer useful and therefore not suitable for dialogue communications. Websites that are regularly updated and contain valuable information because it seems credible to the relevant public and gives the impression that the organization is responsible, thus helping to create the preconditions for dialogical relationships. [9]

- When it comes to retaining visitors, website designers should be careful not to do this by engaging in links from their websites to other useful sites engaging in links from their websites. Once visitors leave the site using the link, they may never return to the original site.

- Generating return visits and retaining visitors and the likelihood of return visits from different publics is an important element in building long-term relationships through organizational websites.

Previous analyzes of the researched possibilities of Internet technologies show that there are numerous possibilities for effective introduction and maintenance of public relations, especially when this activity is contained in one person or manager of a small company. After the establishment of the aforementioned process of establishing public relations, a small entrepreneur should continue to hold synchronous discussions in order to give innovations to all interested parties in one go, and further maintain this through personalization through social networks. In any case, a particularly small entrepreneur at the beginning of the business should organize the process step by step. In conclusion, it can be stated that PR is not only a marketing tool but also one of the important management activities that can be most effectively carried out using Internet technologies.

\section{Discussion}

Analyzing the previous content, one can notice several peculiarities contained in the object of research, which is a small business entity. New theories, new techniques, cultural changes and technological advances all combine to create a dynamic environment within which marketers try to ensure that their messages get through to their target audiences. [13].The basic observation lies in the fact that small enterprises are by all parameters an essential component of all, and especially developed economic systems. The situation is similar in the Croatian economy and thus in the economy of Slavonia and Baranja. This is why small businesses deserve special attention. As a subject and the main goal of the research are public relations or PR. The researched and presented data show that the development of this activity followed at the end of the 19th and the beginning of the 20th century. 
Public relations have gradually changed, especially with the development of new information technologies, so PR has increasingly taken place in terms of synergy of common interests of the company and its public. Research shows that PR is still an important promotional tool in marketing, but it is gaining in importance and is becoming one of the essential management activities especially in a small business. As the essence of the research and confirmation of the hypothesis are the possibilities provided by the development of IT hardware and software. Namely, information technologies provide the possibility of effective public relations with minimal costs and little waste of time. The proposal of the PR application is approached in stages. The goal of such an approach is aimed at the gradual and effective introduction of PR via the Internet.

In addition, the small entrepreneur is enabled to perform permanent education only with a minimum of time and costs. In this sense, the exchange of information in synergy with the environment simply leads to new knowledge in various spheres of interest. The introduction and maintenance of PR is gradually developed towards the goal, which is an allsynchronous discussion that enables mutual communication and information and even education. Teaching relations through social networks can help maintain public relations, because it personalizes everything and thus strengthens the contacts of entrepreneurs with the relevant environment. Given that a small entrepreneur is usually the owner and manager, it is clear that he will personally perform all PR activities himself. The effectiveness of this approach can be seen from the proposed model but also from several of the views cited in the relevant sources.

\section{Conclusion}

More can be deduced from the content analysis and discussion. First of all, small businesses are an important factor in any, especially developed economic system. Problem is that small businesses are not using Internet technology enough in promotion. This is shown by data obtained from relevant foreign and domestic sources. In addition, PR activities should be given special attention because it is part of marketing but also a managerial activity in small businesses. In particular, it should be borne in mind that all creative and management tasks in a small business are performed by one person. Therefore, it is proposed to use Internet opportunities in the introduction and maintenance of public relations in a small business. After analyzing and defining PR as one of the managerial activities, the phased introduction of PR with the help of the Internet is proposed. In that sense, the steps are listed and their functions are explained.

In scientific terms, it has been confirmed that PR in small businesses should also be performed online and introduced in stages. This is confirmed by the analysis of several relevant sources as the fact that PR, especially in small businesses, is not only a marketing tool but also an important managerial activity. In terms of development, PR can be maintained and increase quality in accordance with the development of information technology. This approach can be effective in the application in small enterprises of the Republic of Croatia and the wider region, especially the part that is even at a slightly lower level of economic development. As a direction and goal of future research and scientific plans on the development of public relations, it can be research on the greater role of centers of excellence and especially scientific research educational institutions.

\section{References}

[1] Chen, P. (1976). The Entity-Relationship Model - Toward a Unified View of Data, ACM Transactions and Database Systems, Vol. 1., No. 1. pp 9-36..

[2] Havaš, L., Medved, V., Skočir, Z. (2015). Application of Mobile Technologies in the Preparations for Long Distance Running, Springer International Publishing, pp 85-99.

[3] Office of Advocacy, U.S. Small Business Administration (2010). The Small Business Economy: A Report to the President, Appendix A

[4] Osredečki, E. (1995). Public relations, Edo-Biblioteka poslovnih priručnika, Zagreb, pp.142.

[5] Jonston, J., Zawawi, C. (2004). Public Relatons: Theory and Practice, 2nd.Ed. Allen \& Unwin Croes Nest, Australia, 2004, pp. 390.

[6] Tomić, Z. (2008). Public relations - theory and practice, Synopsis, Zagreb-Sarajevo, pp. 34.

[7] Nowsu,I.E .( 2000), Information Technology as an Indispensable Tool for Public Relations in the New Millennium, Public Relations Journal, Vol.2., No.1,pp. 18

[8] Lentz, I. (2000), 10 commandments for the success of small and medium enterprises, HUP,Zagreb, pp.55.

[9] Ružić, D. (2003) e-marketing, Economic faculty Osijek, pp. 65.

[10] Kim, W., Personalization: Definition, Status and Challenges ahead, Journal of Object Technology, No.1.

[11] Alfred C. W., Morrison, B., B., (2008), Social Networking, IEEE Computer 41(2), pp. 98.

[12] Cooley, T. (1999). Interactive communication - Public relations on the Web. Public Relations Quarterly, Vol.44, No.2, pp. 41-42.

[13] Markova, P, Prajova, V, Salgovicova, J. (2011). "The internet and integrated marketing communications." Annals of DAAAM \& Proceedings, p. 271. 